\title{
Variations in the morphology of retinopathy of prematurity in extremely low birthweight infants
}

\section{W E Schulenburg, G Tsanaktsidis}

Br J Ophthalmol 2004;88:1500-1503. doi: 10.1136/bjo.2004.044669

Aims: To investigate the clinical observations that arteriovenous shunts typical of threshold retinopathy of prematurity (ROP) are morphologically different in extremely low birthweight infants weighing less than $1000 \mathrm{~g}$.

Methods: An observational case series of six extremely low birthweight infants displaying specific features of threshold retinopathy of prematurity enrolled between 1998 and 2001 at one centre. The variant morphology was documented with colour photography and fundus fluorescein angiography before laser therapy.

Results: Stage 3 threshold ROP in extremely premature infants may be characterised by a different morphology not demonstrating classic shunt formation. A poorly developed capillary bed is present in already vascularised retina in these cases.

Conclusions: This case series of extremely low birthweight infants display variations in the typical morphological appearance of threshold ROP. In these cases, established plus disease may be present in the absence of arteriovenous shunting. Delaying treatment until a classic stage 3 ridge with extraretinal neovascularisation develops may be detrimental to controlling the disease process. The authors propose that the criteria for threshold disease requiring treatment do not accurately apply in this extremely low birthweight group as defined by the CRYO-ROP study and that treatment should be instituted before the typical threshold features arise. Plus disease remains the most reliable sign indicating the need for treatment.

A n understanding of the natural history and morphological stages of retinopathy of prematurity (ROP) formed the basis for developing the international classification of ROP. ${ }^{1}$ The multicentre trial of cryotherapy for ROP (CRYO-ROP) established the efficacy of cryoablation of the avascular retina in improving retinal and functional outcomes in infants with threshold ROP. ${ }^{2-5}$ In recent years diode laser therapy has become the treatment of choice, achieving equally or more successful visual outcomes ${ }^{6-8}$ compared with cryotherapy.

Despite the success of the CRYO-ROP trial, visual disability in premature infants remains significant, with $44.4 \%$ of treated eyes demonstrating an unfavourable visual outcome and $27.2 \%$ an unfavourable retinal outcome at 10 years. ${ }^{5}$ The early treatment for ROP randomised trial ${ }^{9}$ was designed to identify high risk prethreshold infants to improve visual outcomes without unnecessarily treating infants. The 1 year results of the trial support retinal ablative therapy in type 1 ROP defined as zone I, any stage ROP with plus disease; zone I, stage 3 ROP without plus disease; or zone II, stage 2 or 3 ROP with plus disease.

The survival rate of very low birthweight (VLBW; 1000$1499 \mathrm{~g}$ ), or extremely low birthweight (ELBW; <1000 g) infants has increased over the past 20 years. ${ }^{10-13}$ Neonates with a gestational age of 25 weeks or less and extremely low birth weight now represent a significant percentage of infants requiring treatment for threshold ROP. ${ }^{14}$ In our experience the majority of cases requiring treatment are 25 weeks or less (unpublished data).

The Hammersmith Hospital in west London is a referral centre for the management of threshold ROP, at which single observer status (WES) has existed since 1982. In recent years we have made observations that the morphology of ROP in some extremely low birthweight infants with a gestational age of 25 weeks or less is distinctly different from that of more mature neonates. The arteriovenous shunts typical of stage 3 ROP appear to be poorly defined in this subgroup and are associated with earlier onset of plus disease (at least two quadrants of dilatation and tortuosity of the posterior retinal blood vessels). We decided to further investigate these observations between 1998 and 2001 at the Hammersmith Hospital.

\section{METHODS}

Over a 3 year period 35 infants fulfilled the criteria for threshold disease requiring treatment. Of these infants, six met our criteria of extremely low birth weight and displayed the variant morphological appearance of interest. These selected infants with a specific morphology were investigated with colour photography and angiography. These infants did not represent all extremely low birthweight cases.

Following detailed informed consent from the parents, each infant underwent colour photography with a modified vertical mounted Oberkochen Zeiss fundus camera and fundus fluorescein angiography. Diode laser therapy (Iridex $810 \mathrm{~nm}$ infrared diode) was performed immediately after fluorescein angiography. Despite fluorescein leakage into the vitreous cavity, this did not interfere with laser uptake in the retina. All infants were treated in the neonatal unit under sedation, ventilation and full monitoring in the presence of a neonatologist. Sodium fluorescein $14 \mathrm{mg} / \mathrm{kg}$, diluted in $2 \mathrm{ml}$ of water, was administered intravenously. The dye transit through the retina was recorded with the fundus camera focusing upon the already vascularised retina and demarcation line. We were specifically interested in assessing the quality of vascular development in the already vascularised retina.

The gestational age of three infants was 24 weeks and of the other three was 25 weeks. Birth weight ranged from $590 \mathrm{~g}$ to $824 \mathrm{~g}$. Post-menstrual age at treatment ranged from 35 to 41 weeks (table 1 ).

Abbreviations: CRYO-ROP, multicentre trial of cryotherapy for ROP; ELBW, extremely low birth weight; FFA, fundus fluorescein angiogram; ROP, retinopathy of prematurity; VLBW, very low birth weight 


\begin{tabular}{|c|c|c|c|}
\hline Patient & $\begin{array}{l}\text { Gestational age } \\
\text { (weeks) }\end{array}$ & Birth weight (g) & $\begin{array}{l}\text { Post-menstrual age } \\
\text { at treatment }\end{array}$ \\
\hline 1 & 24 & 700 & 39 \\
\hline 2 & 25 & 758 & 36 \\
\hline 3 & 24 & 824 & 35 \\
\hline 4 & 24 & 670 & 36 \\
\hline 5 & 25 & 800 & 41 \\
\hline 6 & 25 & 590 & 36 \\
\hline
\end{tabular}

\section{RESULTS}

Colour photographs and fundus fluorescein angiograms (FFA) were recorded in all six infants. The colour photographs were of satisfactory quality in five cases. The quality of FFA in three patients was considered to be satisfactory for analysis. The colour photographs and FFA demonstrated several morphological characteristics not previously reported in acute threshold ROP.

(1) A demarcation line with minimal or no shunting may be associated with marked peripheral congestion and tortuosity (fig 1).

(2) Shunts may be present at the demarcation line but consist of a fine meshwork of well differentiated capillaries on the surface of the retina extending posteriorly onto the vascularised retina (fig 2). This differs from the classic amorphous shunt generally accepted.

(3) In the absence of typical shunts severe posterior pole congestion may be present (fig 3 ).

(4) In one infant (case 2) abnormal capillary proliferation was also present around the optic disc (fig 4). This infant suffered severe chronic respiratory complications and died 2.5 months later. The severity of the capillary proliferation around the disc and on the retinal surface in this case may be explained by extreme retinal ischaemia further compounded by this infant's poor systemic condition.

(5) One infant displayed a better differentiated shunt at the demarcation line (fig 5) but FFA of the corresponding area demonstrated a poorly developed capillary network in the already vascularised retina (fig 6).

(6) One infant demonstrated clusters of preretinal capillary proliferation posterior to the demarcation line confirmed by FFA of the corresponding area (figs 7 and 8).

(7) One infant demonstrated a shunt at the demarcation line consisting of a fine capillary structure. FFA of the

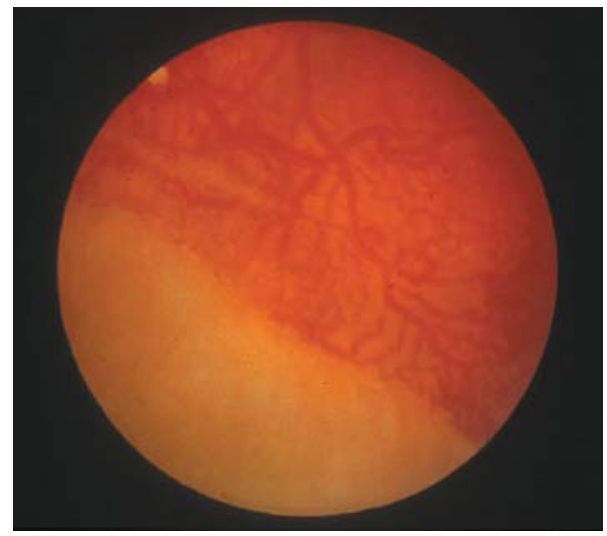

Figure 1 Demarcation line with minimal morphological shunt development and pronounced peripheral congestion.

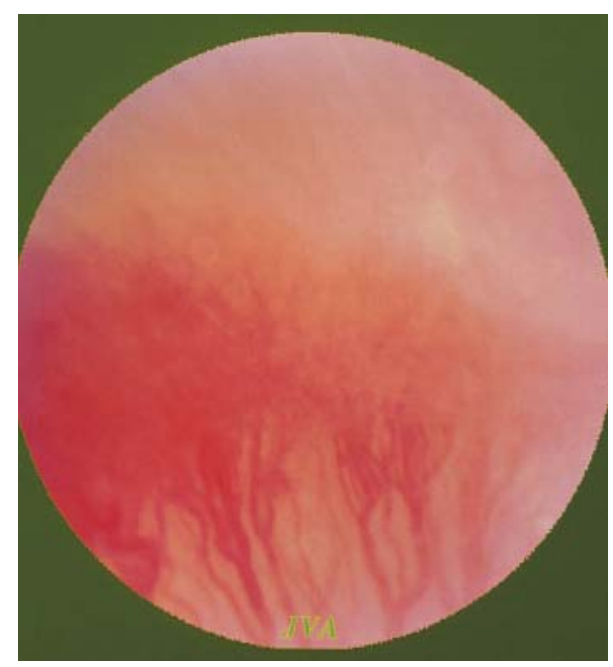

Figure 2 Shunt at demarcation consisting of meshwork of capillaries.

corresponding area demonstrated an extremely poorly developed capillary bed (figs 9-11).

In all six cases the disease process was located in posterior zone 2 .

\section{DISCUSSION}

The case selection for the CRYO-ROP trial ${ }^{2}$ was based upon the morphological appearance of the disease to define threshold status. Our series of extremely low birthweight infants displays variations in the typical morphological appearance for which the criteria for threshold disease do not accurately apply.

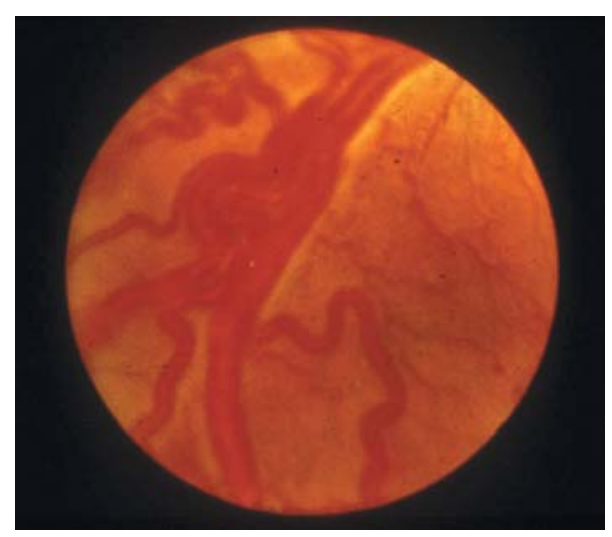

Figure 3 Severe posterior pole congestion in the absence of well developed shunts. 


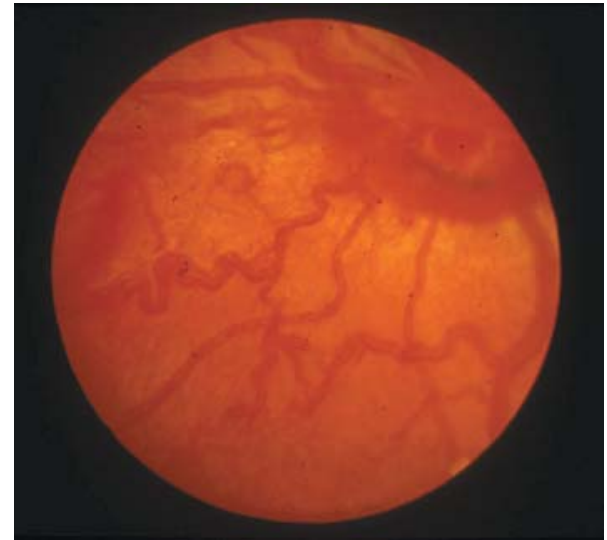

Figure 4 Capillary proliferation around the optic disc.

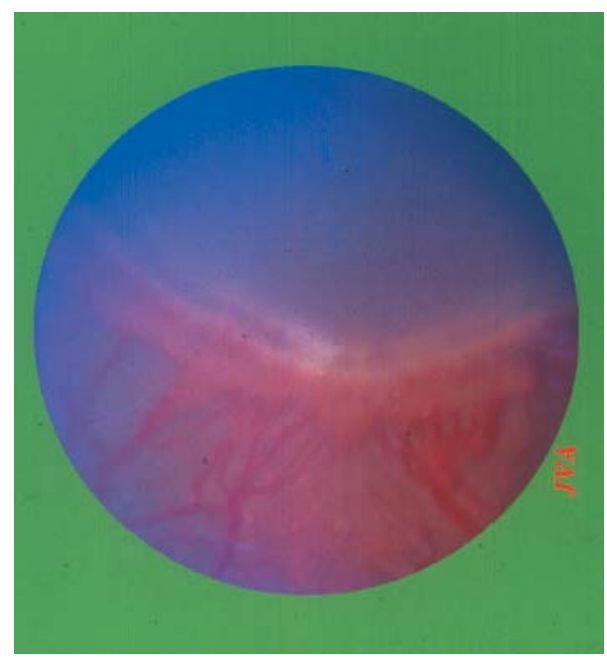

Figure 5 Befter differentiated shunt at demarcation line.

The subgroup described here can be identified by morphology only and does not require routine fluorescein angiography for diagnosis. Fluorescein angiography, however, does raise an interesting question about whether the areas of capillary non-perfusion posterior to the demarcation line should also be treated. In the context of the magnitude of

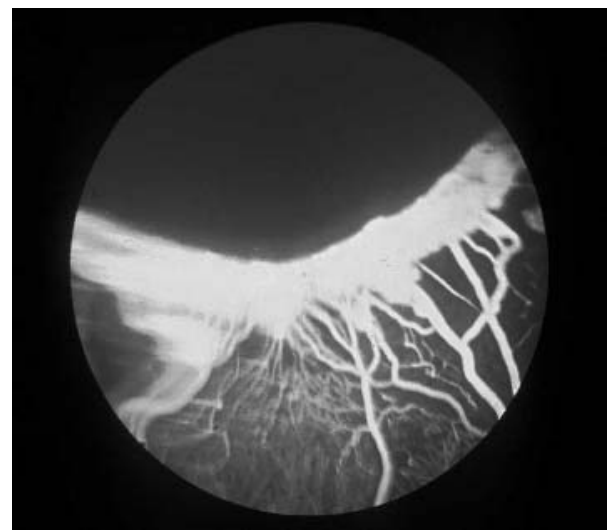

Figure 6 FFA demonstrates poorly developed capillary bed posterior to demarcation line of corresponding area represented by figure 5 .

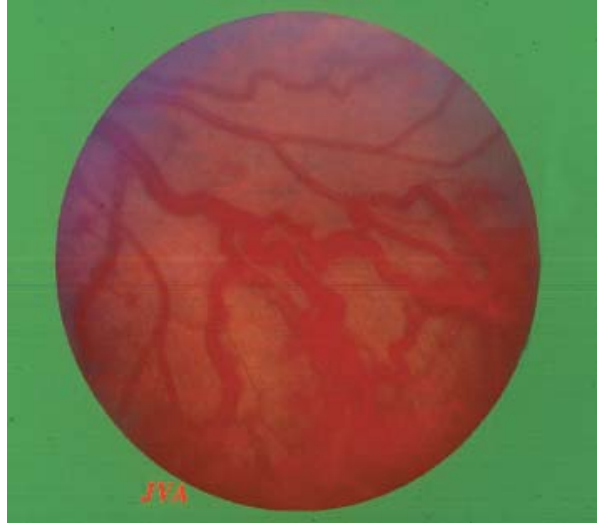

Figure 7 Clusters of preretinal capillary proliferation.

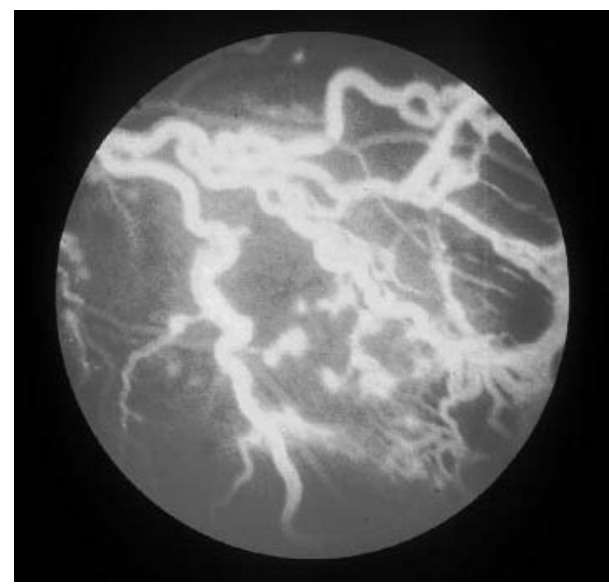

Figure 8 Preretinal capillary proliferation confirmed by FFA corresponding to the area demonstrated in figure 7.

anterior avascular retina, treating the ischaemic areas in already vascularised retina will probably not alter the outcome. However, in cases which fail to regress after the initial laser treatment, two rows of confluent burns posterior to the ridge may be administered during re-treatment as described by O'Keefe et al ${ }^{15}$ and Gole. ${ }^{16}$

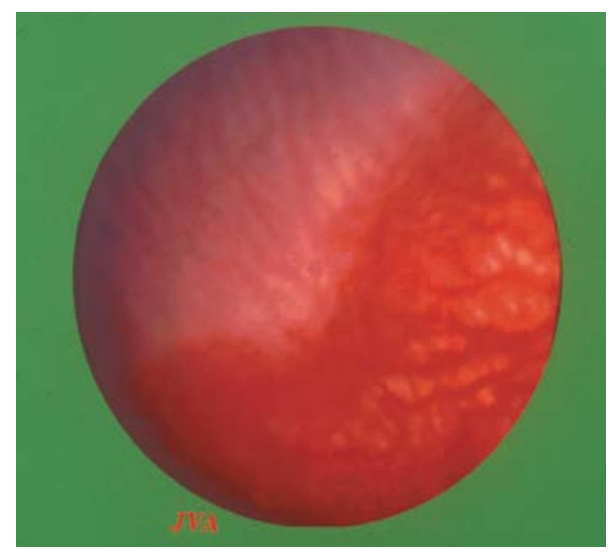

Figure 9 Demarcation shunt consisting of fine capillary structure. 


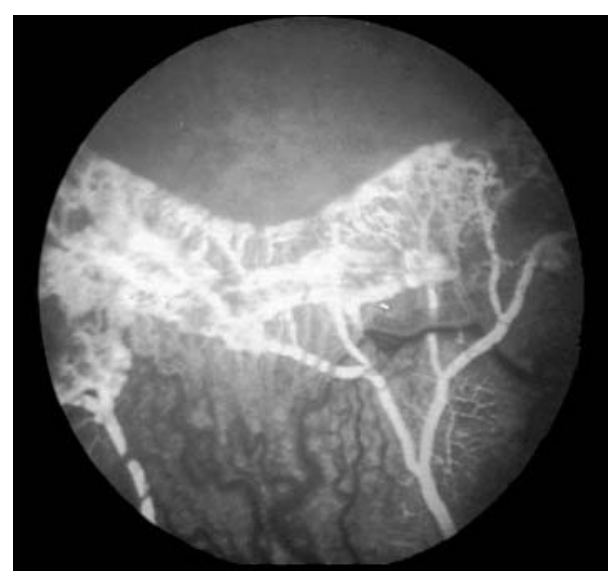

Figure 10 Arterial phase of FFA demonstrating incomplete and poorly developed capillary bed.

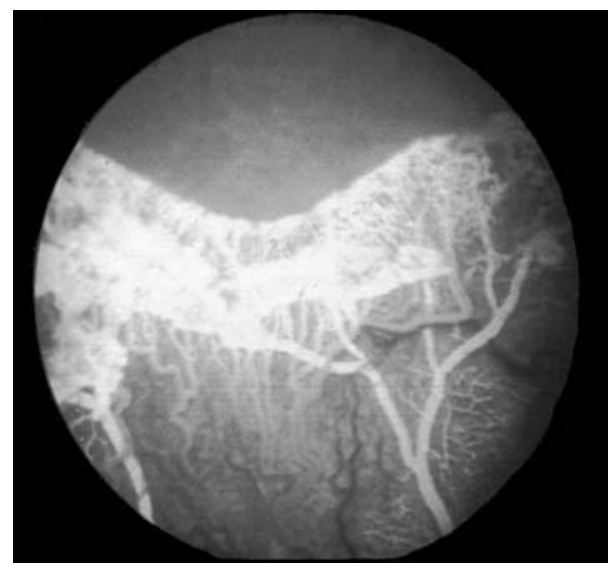

Figure 11 Early venous phase of FFA of corresponding area to figure 10 .

The clinical appearance described here may be explained by the lack of capillary development in the vascularised retina and arteriovenous shunting, causing relative retinal hypoxia, increased levels of vascular endothelial growth factor, vasodilatation and increased vascular tortuosity. The aggressive appearance of rush-type disease and its poor prognosis can be attributed to these factors in extremely low birthweight infants.

The morphology of ROP in the cases reported here is distinctly different from the appearance described in the international classification ${ }^{1}$ and applied in the criteria for threshold ROP. ${ }^{2}$ With the improved survival rate of extremely low birthweight infants ${ }^{14}$ and infants with a gestational age as low as 23 weeks, it is of fundamental importance to recognise this morphological group. Plus disease is frequently reached in these cases without the typical arteriovenous shunts. Failure to recognise this subgroup may delay treatment unnecessarily.

Our results suggest that the presence of plus disease is the most reliable clinical sign of threshold ROP in extremely low birthweight infants. A narrow window of opportunity for treatment exists in these cases with plus disease but without classic peripheral shunts and delay in treatment may result in further progression of the disease from a pure retinopathy to a vitreoretinopathy and cicatricial ROP. The morphology reported here should be considered as a subgroup of ROP with a more serious threat to visual development requiring treatment without delay.

Our paper complements and supports the findings of the early treatment for retinopathy of prematurity randomised trial $^{9}$ in treating zone 1 and 11 prethreshold disease earlier than previously recommended. Although our results refer specifically to extremely low birthweight infants, the clinical findings of poorly developed shunts in the presence of plus disease, and capillary non-perfusion in already vascularised retina have far ranging implications about the nature of ROP itself.

\section{ACKNOWLEDGEMENTS}

We thank Mr John Arnold for his excellent photographic support.

\section{Authors' affiliations}

W E Schulenburg, G Tsanaktsidis, Hammersmith Hospital, Du Cane Road London W12 OHS, UK

Correspondence to: W E Schulenburg, Western Eye Hospital, 171 Marylebone Road, London NW1 5YE, UK; edschulenburg@blueyonder. co.uk

Accepted for publication 25 May 2004

\section{REFERENCES}

1 The Committee for the Classification of Retinopathy of Prematurity. An international classification of retinopathy of prematurity. Arch Ophthalmol 1984:102:1130-34.

2 Cryotherapy for Retinopathy of Prematurity Cooperative Group. Multicenter trial of cryotherapy for retinopathy of prematurity. One-year outcome-structure and function. Arch Ophthalmol 1990;108:1408-16.

3 Cryotherapy for Retinopathy of Prematurity Cooperative Group. Multicenter trial of cryotherapy for retinopathy of prematurity. 31/2-year outcomestructure and function. Arch Ophthalmol 1993;111:339-44.

4 Cryotherapy for Retinopathy of Prematurity Cooperative Group. Multicenter trial of cryotherapy for retinopathy of prematurity. Snellen visual acuity and structural outcome at $5 \frac{1}{2}$ years after randomization. Arch Ophthalmol 1996:114:417-24.

5 Cryotherapy for Retinopathy of Prematurity Cooperative Group. Multicenter Trial of Cryotherapy for Retinopathy of Prematurity: ophthalmological outcomes at 10 years. Arch Ophthalmol 2001;119:1110-18.

$6 \mathrm{Ng} \mathrm{EY}$, Connolly BP, McNamara JA, et al. A comparison of laser photocoagulation with cryotherapy for threshold retinopathy of prematurity at 10 years: part 1. Visual function and structural outcome. Ophthalmology 2002;109:928-34, discussion 935.

7 Connolly BP, $\mathrm{Ng} \mathrm{EY,} \mathrm{McNamara} \mathrm{JA,} \mathrm{et} \mathrm{al.} \mathrm{A} \mathrm{comparison} \mathrm{of} \mathrm{laser}$ photocoagulation with cryotherapy for threshold retinopathy of prematurity at 10 years: part 2. Refractive outcome. Ophthalmology 2002;109:936-41.

8 Laser ROP Study Group. Laser therapy for retinopathy of prematurity. Arch Ophthalmol 1994;112:154-6.

9 Early Treatment for Retinopathy of Prematurity Cooperative Group. Revised indications for the treatment of retinopathy of prematurity. Arch Ophthalmol 2003;121:1684-96.

10 Cartlidge PH, Stewart JH. Survival of very low birthweight and very preterm infants in a geographically defined population. Acta Paediatr 1997:86:105-10.

11 Alexander GR, Kogan M, Bader D, et al. US birth weight/gestational agespecific neonatal mortality: 1995-1997 rates for whites, hispanics, and blacks. Pediatrics 2003;111:e61-6.

12 Darlow BA, Cust AE, Donoghue DA. Improved outcomes for very low birthweight infants: evidence from New Zealand national population based data. Arch Dis Child Fetal Neonatal Ed 2003;88:F23-8.

13 Harper RG, Rehman KU, Sia C, et al. Neonatal outcome of infants born at 500 to 800 grams from 1990 through 1998 in a tertiary care center. J Perinatol 2002;22:555-62.

14 Finnstrom O, Olausson PO, Sedin G, et al. The Swedish national prospective study on extremely low birthweight (ELBW) infants. Incidence, mortality, morbidity and survival in relation to level of care. Acta Paediatr 1997;86:503-11.

15 O'Keefe M, Burke J, Algawi K, et al. Diode laser photocoagulation to the vascular retina for progressively advancing retinopathy of prematurity. Br J Ophthalmol 1995;79:1012-14.

16 Lee GA, Hilford DJ, Gole GA. Diode laser treatment of pre-threshold and threshold retinopathy of prematurity. Clin Experiment Ophthalmol 2004;32:164-9. 